See discussions, stats, and author profiles for this publication at: https://www.researchgate.net/publication/319042518

\title{
Transit-Oriented Economic Development: The Impact of Light Rail on New Business Starts in the Phoenix, AZ Region
}

Article in Urban Studies · July 2017

DOI: $10.1177 / 0042098017724119$

CITATIONS

26

1 author:

8. Kevin Credit
15 PUBLICATIONS 69 CITATIONS
SEE PROFILE
READS

737 


\title{
Transit-Oriented Economic Development: The Impact of Light Rail on New Business Starts in the Phoenix, AZ Region
}

Note: author's submitted version (5/11/17)

\author{
Kevin Credit \\ Ph.D. Candidate \\ Department of Geography \\ Michigan State University \\ Geography Building \\ 673 Auditorium Road, \\ East Lansing, MI 48824 \\ Email: creditke@msu.edu
}

\begin{abstract}
This article examines the impact of Phoenix's light rail system, which opened in 2008, on new firm formation in specific industries. Individual business data from 1990-2014 are used in a quasi-experimental adjusted-interrupted time series (AITS) regression to compare the impact of the transit system's construction on new business starts in 'treatment' and 'control' areas before and after the opening of the line. Findings show that the transit adjacency is worth an $88 \%$ increase in knowledge sector new starts, a $40 \%$ increase in service sector new starts, and a $28 \%$ increase in retail new starts at the time the system opened, when compared with automobileaccessible control areas. However, the light rail also appears to suffer from a 'novelty factor' after the initial increase in new establishment activity in adjacent block groups, the effect diminishes at the rate of $8 \%, 6 \%$, and $7 \%$ per year, respectively. The results also provide insight into the spatial extent of light rail impacts to new business formation, with areas 1 mile from stations observing $21 \%$ fewer retail new business starts and $12 \%$ fewer knowledge sector new starts than areas within $1 / 4$-mile of stations.
\end{abstract}

\section{Keywords}

Transit-Oriented Development (TOD), entrepreneurship, light rail, built environment, planning

\section{Acknowledgements}

Thanks to Dr. Elizabeth Mack for providing considerable assistance with helping to refine the analysis, provide suggestions, and revise previous drafts of this paper. Thanks also to Lisa-Marie Pierre and Jonah White for helping to edit the revisions, and also to Walls \& Associates for the prepared NETS data, without which the analysis wouldn't be possible. 


\section{Introduction}

Over the last thirty years in the United States, billions of tax dollars have been spent on the construction of some 650 miles of light rail lines in 16 regions, with nearly 150 additional miles planned or under construction (as of 2014) (Freemark, 2014). Most of these new systems and complimentary transit-oriented development (TOD) schemes - have been touted as economic development tools to catalyze infill development and reinvestment in central cities. But, despite a multitude of studies into the influence of rail transit on station-area property values, much remains unknown about the economic impact of transit investments (Cervero and Landis, 1997; Cervero, 2004; Agostini and Palmucci, 2008; Golub et al., 2012). In order to foster more sustainable regions, planners, academics, and policy makers require a better understanding of the specific ways in which infrastructure and policy influence regional economic growth.

Property values are a useful way to quantify the impact of transportation investments, but they only provide one piece of a complex picture. There are other ways to look at the regional and local economic impacts of transit stations which have been only lightly addressed in the transit and economic development literature to this point. Impacts to new business activity are particularly important to consider, as new businesses make important contributions to regional economic growth and diversity (Wennekers and Thurik, 1999; Frenken et al., 2007). While recent research has begun to investigate the link between transit and new business creation (Chatman, Noland, and Klein, 2016; Song, et al., 2012), these studies do not explicitly evaluate the spatial extent of transit's impact on new business starts. By using an "adjusted interrupted time series" (AITS) Poisson regression methodology to analyze new business point data in Phoenix, Arizona from 1990-2014, this paper delivers a quasi-experimental examination of transit's impact on new business formation, providing estimates of the distance decay function 
for entrepreneurial benefits related to transit infrastructure (Galster et al., 2004). In so doing, this paper answers two important questions. First, what impact does the construction of a new transit line have on adjacent new business activity in the retail, service, and knowledge industries, when compared to 'baseline' business activity in more automobile-centric neighborhoods? And, second, how do these impacts vary as distance from the new stations increases?

The Phoenix metropolitan area provides an important context in which to study the effects of new transit system construction and associated transit-oriented development. It is one of the largest and fastest-growing regions in the United States, having more than doubled in population from 2.1 million in 1990 to almost 4.7 million in 2016 (NHGIS, 1990; US Census, 2016). As such, it is a key representative of the American 'Sunbelt' - warm-weather regions that that have attracted the largest gains in population since World War II, but often without investment in fixed transit infrastructure and an over-reliance on sprawling, automobile-oriented development patterns (Economist, 2017).

The analytical approach used in this paper demonstrates the role of light rail in catalyzing firm establishment in station-adjacent neighborhoods. The results show that, since the light rail line has been operational, neighborhoods within walking distance (1-mile) of transit stations have experienced a substantial increase in new business starts in the knowledge, service, and retail sectors when compared with automobile-accessible control areas. However, this increase in the absolute number of businesses erodes over time, suggesting the presence of a 'novelty factor' for the system (Mohammed et al., 2013). The results also provide insight into the spatial extent of light rail impacts to new business formation, with areas 1 mile from stations observing $21 \%$ fewer retail new business starts and $12 \%$ fewer knowledge sector new starts than areas within $1 / 4$ mile of stations. Given the spatial context of business location and planning policy decisions, the 
geographic character of transit's impact on business formation is particularly important for policy-makers and entrepreneurs to understand, and could help guide future station-area planning processes in other regions.

\section{Theoretical Context}

Transit-oriented development is a theoretical planning concept designed to help mitigate the negative externalities of suburban sprawl (Calthorpe, 1993; Brueckner, 2000; Newman and Kenworthy, 2013). The idea, which has now been implemented in several cities in North America, is based off of Peter Calthorpe's "pedestrian pocket" (1993), and involves creating small nodes of walkable urbanism that are connected to the rest of the region by transit.

TOD has several attractive features for promoting urban sustainability. By providing complimentary development around transit stations, it increases use of the regional transit network, thus decreasing congestion, automobile pollution, traffic deaths, and other negative externalities associated with suburban environments (Brueckner, 2000; Ewing, 1997). TOD also provides new options to meet the unmet demand of consumers who would prefer to live in a walkable community but cannot find housing in areas that meet their financial or employment needs, which - according to some sources - is substantial (ULI, 2015; APA, 2014).

Most importantly for this paper, TOD fosters economic development around new transit stations, which have a built-in market potential that is sometimes not realized due to poor station accessibility (Newman and Kenworthy, 2013). This increased development potential can be used as both an engine for new business formation and an economic revitalization tool for areas that are suffering from extreme disinvestment.

Much of the related literature focuses on implementation and design principles for successful TOD (Dittmar and Ohland, 2004; Curtis et al., 2009). Empirical research on the 
economic benefits of TOD - which focuses heavily on property-value impacts - is generally mixed in its conclusions. There is some evidence that transit generally has a positive effect on property values and/or local business development, especially when a) the transit service itself is high-quality and b) the project is developed in conjunction with land-use planning that maximizes the accessibility benefits conferred by the investment development (Damm et al., 1980; Landis et al., 1994; Knapp et al., 2001; Cervero, 2004; Agostnini and Palmucci, 2008; Mohammed et al. 2013). Light rail systems in particular have been shown to confer economic benefits to the value of properties in proximity to stations, generally with a 'nuisance' penalty in value for those properties directly adjacent to the tracks (Weinberger, 2001; Weinstein and Clower, 2003; Golub et al., 2012). In addition, recent research shows that commercial properties (or land) tend to be much more highly impacted by rail investments than residential properties, and "the perceived benefit of the rail system at time of announcement is often higher compared to the actual realized benefit after the system stabilizes," a result that speaks to the novelty factor of new transportation infrastructure (Mohammad et al., 2013).

However, other studies find that the connection between transit and economic development is dependent primarily on the underlying context of the region (Vessali, 1996; Giuliano, 2004; Schuetz, 2014). Some question the extent to which TOD is able to promote compact development, reduce automobile use, and provide secondary economic benefits (Quinn, 2006; Bollinger and Ihlanfeldt, 1997; Chatman, 2013). Giuliano raises the issue that economic growth observed due to transit development may simply be a re-focusing of development that would have occurred somewhere else (2004). Other work has found a significant difference in the new business-creating impact of transit systems in different types of regions, with the more 
auto-centric planning policies of Dallas-Ft. Worth perhaps fostering reduced economic impact from rail systems (Chatman, Noland, and Klein, 2016).

So, despite a large research effort into the economic impacts of transit systems, key questions remain as to the spatial impacts of transit infrastructure on new business formation, as well as the presence of a 'novelty factor' in transit system use, and the viability of TOD in more auto-oriented regional environments.

\section{Conceptual Framework}

While property values capture the economic benefits provided by transit systems, they do not speak to the specific role of transit in fostering new business formation. This underexplored relationship is central to this paper's thesis, because new businesses benefit cities in several ways that go beyond direct monetary impacts. New businesses serve as conduits for innovative activity and knowledge spillovers (from parent companies or large research institutions). In addition, the knowledge spillovers and innovations that some new firms develop have the potential to diversify the industrial base and provide protection from economic shocks to particular sectors (Jacobs, 1967; Frenken et al., 2007). Finally, a variety of new (often small) businesses has the potential to add significantly to the land use diversity and urban vitality that planners have long espoused (Jacobs, 1961). While entrepreneurship is critical to the economic development of cities, its connection to transportation requires further study. Figure 1 shows a variety of economic benefits that transit infrastructure provides to businesses of different types.

\section{[INSERT FIGURE 1]}

Social networks, trust, and "weak" ties fostered by face-to-face contact and relationship building are important components of contemporary business success, especially for firms in industries that require strong interpersonal client relationships, such as producer services 
(Gordon and McCann, 2000; Nelson, 2005; Storper and Venables, 2004). Social embeddedness is also particularly important for new, small businesses that rely on local networks and personal contacts to survive (Robinson et al., 2004, Stam, 2007).

More traditional agglomeration benefits are also fostered by transit infrastructure. Transit provides increased regional access to labor markets, particularly for businesses without specialized hiring needs, such as retail, personal services, and hospitality (Chatman, Noland, and Klein, 2016; Chatman and Noland, 2011; Rosenthal and Strange, 2003). By supporting informal interaction, casual socialization after work, chance encounters, and reflection, transit can help foster the knowledge spillovers and information exchange that have been identified as key drivers of innovation in the knowledge economy (Chatman and Noland, 2011; Asheim et al., 2011; Saxenian, 1994). Transit is particularly well-suited to foster these benefits, as they exist only over relatively short distances (Rosenthal and Strange, 2003). While knowledge spillovers can benefit businesses in all sectors, they are particularly useful for firms in the knowledge industries, producer services, and education. On the other hand, benefits from a larger market area and higher visibility are most likely to benefit customer-oriented firms like retailers, service providers, and hospitality businesses, for which visibility plays an important role in start-up location decisions (see, e.g., Bradley University, 2008). In an urban context, transit stations function as primary transportation nodes, increasing the visibility of surrounding businesses and providing access to a larger market area and increased demand potential.

Finally, transit plays a role in fostering an urban, car-free lifestyle that may be attractive to the millennial generation (Weissmann, 2012; APA, 2014; ULI, 2015; RSG, 2014). As researchers like Richard Florida have theorized, the new creative economy is driven by highlyskilled workers with specific kinds of neighborhood preferences (2002; 2004). This reverse type 
of labor sorting has helped fuel a burgeoning "back-to-the-city" movement and increasing demand for urban amenities (Hyra, 2015). While the extent to which this trend constitutes a real shift in urban development remains to be seen (Sturtevant and Jung, 2011), businesses interested in fostering socially-conscious or environmentally-friendly images to recruit younger, talented workers - especially those in competitive creative industries such as high-tech or producer services - may play an increasing factor now and into the future (Orlitzky et al., 2003; Hammann et al., 2009; Florida, 2002).

Given the variety of reasons why new businesses in particular industries might find an advantage from locating near transit stations, this paper explores the transit-entrepreneurship relationship in more detail by studying the rate of new business formation in three sectors particularly influenced by transit's accessibility benefits. Retail businesses (NAICS 44-45) include stores selling retail goods, from cars to home goods, and grocery stores to office supply stores. Knowledge businesses (NAICS 51-52 and 54-55) include firms in the information sector like software publishers, finance and insurance companies like banks, and professional and scientific services like lawyer's offices and management consulting firms. Services (NAICS 72 and 81) include hotels, restaurants, bars, and other personal services like dry cleaning and barber shops.

\section{Study Area and Data}

The Phoenix metropolitan area is a particularly interesting region in which to study the effects of light rail construction on entrepreneurship, for several reasons. First, its population has grown dramatically since 1990, and is now the twelfth largest metropolitan area in the United States (NHGIS, 1990; US Census, 2016). Second, it exemplifies the large-scale demographic shifts that have taken place in the US since the end of WWII, as millions have left the industrial 
Midwest and East Coast for warmer cities in the 'Sunbelt', like Phoenix, Orlando, Houston, and Atlanta (Economist, 2017). In terms of urban form, the hasty growth in these areas has largely been automobile-focused and sprawling. This makes the introduction of rail transit - and its economic impacts - an interesting object of study in regions like Phoenix, where the existing land use and behavioral patterns do not necessarily support transit-oriented development or ridership. The analysis of spatial and temporal trends in new establishments provided by this paper is especially important as additional Sunbelt cities consider transit projects aimed at increasing transit-oriented development and investment.

The business location data for this paper comes from two separate sources, both based on the Dun and Bradstreet business database. For 1990-2009, the paper uses 2012 National Establishment Time Series (NETS) data prepared by Walls and Associates; for 2010-2014, the data come from ESRI Business Analyst (Walls and Associates, 2012; ESRI, 2014). Dun and Bradstreet collect data on every business establishment in the country, providing a near census of the business population. Also, this data provides much greater coverage of very small and selfemployed establishments compared with federal data sources, making it an ideal source to study the full pattern of entrepreneurship over time (Walls and Associates, 2012). The decision to combine two different datasets comes from the necessity of measuring impacts after the light rail line opened in 2008 .

Between 1990 and 2009, a business is considered a new start if it is a non-branch plant domestic establishment with at least one employee that did not relocate ${ }^{1}$. Due to the limited nature of the ESRI data, for 2010-2014 a business is included in the analysis only if it survived until 2014 and had at least one employee; relocation, branch-plant, and foreign-ownership

\footnotetext{
${ }^{1}$ For NETS data, the businesses are geocoded to their last location. This makes it necessary to consider only businesses that did not relocate to ensure that the spatial locations of the points are correct.
} 
information is not included. Despite the discrepancies between the two datasets, the data used are the same (by year) for both the control and treatment areas; thus, any systematic bias in the way that the data are collected would impact both areas equally. The business points are divided by industry and opening year and spatially joined to 2010 Census blocks.

In order to create a stable boundary for the inclusion of secondary Census data from 1990, 2000, and 2010 in the analysis, demographic data from 1990 and 2000 were first joined to their corresponding Census block geographies. These polygon shapefiles were then converted to points and spatially-joined to the 2010 Census blocks. The counts attached to these points were then summed and divided by their corresponding summed total to create a percentage for the variable that matches the 2010 Census block boundary. Additional control variables available at the point level - such as the number of existing retail, manufacturing, and information businesses in each block in each year - were then spatially joined to the stable 2010 Census geography.

\section{Methods}

In order to gauge the economic impact of the light rail over time, this paper uses the AITS methodology of Galster et al. (2004). This method uses time series data in a regression framework to compare the change in a given variable of interest - in this case, the count of new business starts in specific industries by Census block - between an identified treatment area and a control area, both before and after the point of intervention. In this paper the intervention point is 2008 , when the light rail system opened.

Methodologically, AITS is somewhat similar to other difference-in-differences approaches that have been used in previous studies to determine the impact of policy interventions on neighborhood characteristics (Tranel and Handlin, 2006), including in rail transit contexts (Pagliara and Papa, 2011). AITS, however, goes beyond the standard difference- 
in-differences technique by explicitly accounting for the change in both the absolute value and trend of the dependent variable before and after the intervention. One of the strengths of the method is that it statistically models differences both cross-sectionally (between the treatment and control areas) and longitudinally (between the pre-intervention and post-intervention time periods of the impact area). This provides a robust estimate of the impact of a particular policy intervention, despite the many different forces at work at any given time in complex urban environments (Galster et al., 2004).

\section{Treatment and Control Area Selection}

As with any quasi-experimental study design, the selection of the treatment and control areas deserves care. Rather than selecting an arbitrary boundary for these areas, this paper explicitly tests a range of definitions in order to find the combination with the most similar preintervention trend. For the light rail treatment area, network-based buffers using the US Census 2015 TIGER/Line road shapefile are calculated for $1 / 4,1 / 2$, and 1 mile (corresponding to 5, 10, and 20 minute walks, respectively) around each transit station to form three possible treatment area boundaries. Ranges from $1 / 4$ to $1 / 2$ mile have been cited previously in the literature as the standard area of impact around transit stations (Mohammed et al., 2013; Guerra et al., 2011; Calthorpe, 1993; Zhao et al., 2003); the larger 1 mile boundary is included in order to test whether light rail impacts to business creation might extend beyond this typically-assumed range.

Given this paper's interest in comparing the impact of the automobile and light rail modes on business formation rates, the control area is similarly-defined by network-based buffers calculated around major intersections (selected based on functional classification ${ }^{2}$ ) for 10 minute

\footnotetext{
${ }^{2}$ Major intersections were selected first by identifying intersections between US, State, and Interstate highways within the cities of Phoenix, Mesa, and Tempe. A geographically-representative group of additional intersections between these roads and other major arterials was also added in order to ensure ample coverage.
} 
drives at average speeds of $15 \mathrm{mph}, 30 \mathrm{mph}$, and $45 \mathrm{mph}(2.5,5$, and 7.5 miles, respectively), which represent different ways to conceptualize automobile accessibility. Figure 2 shows the six boundary definitions considered for analysis, as well at the location of the light rail stations, light rail line, major intersections, and highways.

\section{[INSERT FIGURE 2]}

In quasi-experimental study design, it is important to select treatment and control groups that have similar pre-intervention trends in the variable of interest to limit selection bias and provide greater confidence that post-intervention differences between the groups are in fact due to the intervention and not some pre-existing differences between the groups. In order to select the most similar combination of treatment and control areas, the average number of new business starts per year (in each of the three industries of interest) was plotted on a graph for each of the six boundaries considered. OLS was then used to obtain an equation for the linear trend of new business starts over time for each of the boundary definitions. The slope coefficients for each of these equations (which indicate the average linear trend for the given boundary definition) were then compared for each of the nine possible combinations of treatment and control areas, as shown in Appendix A. The boundary combination with the least difference between slope coefficients (i.e., the most similar trend) was the 1 mile treatment area and the 7.5 mile control area, which was then used in the estimation of the AITS model. Appendix B contains graphical depictions of the average trend in new business formation by block for this selected boundary definition for each of the three types of businesses of interest.

\section{Specification of the AITS Model}

The specification of the AITS model used in this paper follows the basic equation laid out by Galster et al. (2004), but uses a Poisson regression model to assess the relationship between 
the variables. The dependent variable, in this case, is the count of new businesses (by block) for each of the three industries of interest: retail, knowledge, and services. Poisson models are preferred in the use of count data, and work on the assumption that the dependent variable has a Poisson distribution, with the natural log of its expected value modeled linearly (UCLA 2007; Faraway 2006):

$$
\log \left(\mu_{i}\right)=\log (\delta)+z \gamma+x \beta
$$

where $\mu$ is the mean of the Poisson distribution of the dependent variable for a given industry of interest, $i$; $\delta$ is an exposure variable that standardizes the dependent variable count by a set exposure (rate); $z$ is a vector of dummy and trend variables that control for pre-intervention (and overall) differences between the treatment and control areas and identify post-intervention differences in both the trend and absolute value of the dependent variable; $x$ is a vector of relevant non-collinear sociodemographic, economic, and spatial covariates (the independent variables); $\gamma$ and $\beta$ are the regression coefficients for the given explanatory variables $\alpha$ and $x$, respectively. Appendix $\mathrm{C}$ shows the variables used in the final AITS specification. The AITS model used in this paper was run in Stata version 13.1 using the "poisson" command, after converting the relevant time-series data from "wide" to "long" format.

Even with the careful selection of treatment and control areas, differences are sure to exist between any experimental groups chosen in complex urban environments. The unique benefit of AITS is that it controls for these inevitable differences using a set of dummy and trend variables. The DIMP variable controls for absolute differences in the pre-intervention values of the dependent variable between the control and treatment groups, while the TRIMP variable controls for differences in the pre-intervention trend in the dependent variable between the two 
groups. In addition, the TRALL trend variable controls for the overall trend, ensuring that a significant result is not simply an artifact of large-scale trends affecting both areas.

In addition to these controls, other variables (shown in Appendix C) are included in the model in order to ensure that other specific differences between the treatment and control areas do not bias the results, including controls for spatial autocorrelation at two scales - regional and local. A dummy variable denoting location in one of the region's downtown business districts generally controls for regional spatial autocorrelation, while a spatial lag of the average value of the dependent variable in neighboring blocks controls for local spatial autocorrelation, or the fact that high values of new starts in one block may be significantly impacted by high values of new starts in the neighborhood (Ward and Gleditsch, 2008). Additional variables ${ }^{3}$ control for demographic differences between blocks, business dynamics, general economic characteristics, and the built environment characteristics of each block.

Finally, in order to test whether the intervention is significant or not - to answer the research question of the paper - a dummy variable denoting the absolute value of the dependent variable in only the treatment area for only the post-intervention time period is included (DPOSTIMP) in the model, as well as a trend variable for only post-intervention observations in the treatment area (TRPOSTIMP). Given the careful study design employed in this paper, a significant positive result for DPOSTIMP indicates that the light rail made an impact on the absolute number of new businesses in the treatment area. Similarly, a significant positive result for the TRPOSTIMP variables indicates that the slope of the trend line for new business starts in the treatment area has shifted upward due to the construction of the light rail.

\section{Results}

\footnotetext{
${ }^{3}$ Correlation matrices (available upon request) were used to assess collinearity between a larger set of potential covariates. Confounders were removed from the final specification, leaving those listed here.
} 


\section{Socioeconomic Context of Light Rail Station Locations}

Before describing the model results, it is important to develop a socioeconomic context for the light rail station locations, since transit investments are always linked to a region's socioeconomic stratification and political decision-making processes. To do this, an adjusted Darden-Kamel Composite Index (Darden et al., 2010; Darden and Kamel, 2000) was created at two scales - the regional and station-area - in order to better understand how socioeconomic factors influence planning for the overall path of the light rail system, as well as the specific location of individual stations. The index uses eight relevant indicators (by Census block group) in 2000, one year after the first proposal for the Phoenix light rail line was developed (Golub et al., 2012): per capita income, public assistance income, unemployment rate, homeownership rate, percent Bachelor's degree attainment or higher, percent of workers in management and professional occupations, median contract rent, and median housing value. The index was calculated by summing the z-score for each of the eight variables, and then dividing the resulting values into quartiles at two scales: 1) based on the entire region's index scores, and 2) based on the index scores of just the 1-mile light rail treatment area, which generally represents stationadjacent neighborhoods. Each block group falls into one of the following categories: low, medium-low, medium-high, and high socioeconomic status (SES).

Figure 3 includes the number and percentage of block groups containing stations in each of the socioeconomic status categories for both boundaries. Interestingly, at the regional scale, a very small number of stations are located in block groups with high or medium-high SES, supporting the political evidence that the wealthiest areas - including cities like Scottsdale declined to be connected to the light rail line. It also reflects the obvious correlation between high socioeconomic status and suburban/exurban areas in which light rail planning makes little 
sense due to reduced population density and sprawling land use patterns. However, if the analysis is confined only to block groups that intersect a 1-mile network buffer of stations - that is, examining the fine-grained spatial decision-making process for individual station locations within the general path of the rail line - over $61 \%$ of block groups with stations have mediumhigh or high SES. This shows that, within the context of fine-grained decision-making, station locations are spatially-biased towards block groups with higher socioeconomic status. They are also driven by a desire to connect large employers, entertainment facilities, and institutions in downtown Phoenix and Tempe. This is important to understand when interpreting the AITS model results, since the location of the light rail line itself - as well as associated entrepreneurship and economic investment - is influenced by regional and local social conditions. Even though the light rail might significantly impact new business starts, these business are still likely to be located in relatively-higher SES areas (due to the location of the stations) and thus perhaps less likely to directly impact disadvantaged populations and spur revitalization.

[INSERT FIGURE 3]

\section{Descriptive Statistics}

Descriptive statistics for the variables used in the model are shown in Appendix D. They provide a general overview of the economic context for both the treatment (1-mile) and control (7.5-mile) areas. In general, the blocks closest to the light rail station show slightly higher levels of new business starts in the three industries of interest over the time period, with the biggest average difference in knowledge sector new starts. Economic variables are also found in higher average quantities in the treatment area, including average employment density (10.92 employees per acre to 1.83) and the percentage of existing retail, manufacturing, and information 
establishments, which makes some sense due to the larger proportion of blocks within downtown business districts (7.9\% to .4\%). The built environment and demographic variables are relatively similar between the two areas, except that average block length and block size are smaller in the treatment area than in the control area.

Descriptive statistics for the pre- and post-intervention characteristics of the 1-mile treatment area are shown in Appendix E. Population, employment density, the percentage of existing businesses in the retail and information sectors, the percentage of population that is black non-Hispanic, and the percentage of the population aged 19-64 all increased slightly in the post-intervention time period; interestingly, only the percentage of existing manufacturing businesses decreased. On the other hand, there are slightly fewer new starts in each industry (on average) in the post-intervention time period than in the pre-intervention time period. However, it is not possible from looking at these raw averages to know whether these drops were higher or lower than the baseline trend in the auto-oriented control areas, or what the post-intervention impact is after controlling for important intervening factors, such as location in a downtown business district. In order to obtain the direct statistical impact of the light rail while controlling for such differences and trends, the AITS model must be used.

\section{AITS Model Results}

The results of the AITS regression, incidence rate ratios (IRR), and percent change values $(1-I R R)$ in the dependent variable for a one-unit increase in a given covariate are shown in Table 1. IRR are calculated as $e$ raised to the power of the given coefficient value, and are reported as numeric figures in Table 1, while 1-IRR values are reported as percentages (Rodriguez, 2007; UCLA, 2007). All of the variables included in Table 1 are statisticallysignificant at a $p$-value of .05 or less. 


\section{[INSERT TABLE 1]}

The DPOSTIMP variable is significant and positive for all three dependent variables, indicating that the treatment area shows a significantly higher number of new business starts per acre in each block than the control area. The light rail line increases new starts in the knowledge sector most significantly, with location in the treatment area from 2008-2014 worth an 88\% increase in new knowledge business starts compared to the control area. There are also $40 \%$ more new starts in the service sector and $28 \%$ more new starts in the retail sector in the treatment area from 2008-2014, indicating that the light rail fostered new business activity in all three sectors of interest.

At the same time, this advantage is on a downward trend, indicated by the results for the TRPOSTIMP variable in all three regression equations. Each year after 2008, the number of knowledge new starts decreased by $8 \%$ in the treatment area compared to the control area. Similarly, the treatment area's advantage in service and retail new starts decreased by $6 \%$ and $7 \%$, respectively, in the post-intervention time period. In simple terms, these results show that the light rail had a significant initial effect on new business starts in all three industries at the time it opened, but this impact has eroded consistently as time has passed since its opening.

As for the control variables, a few interesting relationships stand out. A $10 \%$ increase in black population relates to an $8.6 \%$ increase in retail new starts and a $14 \%$ increase in service new starts, but a $3.3 \%$ decrease in knowledge sector new starts, perhaps indicating the segregated nature of new business location decisions in Phoenix (Bolin et al., 2005). Also, as expected, the business district dummy variable is significant and positive for each of the three dependent variables and shows a substantially high coefficient value. Location in a downtown business district over this time period is worth over $250 \%$ additional new starts per block; however, the 
variable's inclusion in the model does not alter the significance of the DPOSTIMP and TRPOSTIMP factors. Therefore, this analysis shows that the light rail's effect on new business formation functions independently of the positive entrepreneurial environment of downtown districts.

The average number of new starts of a block's contiguous neighbors also significantly impacts each of the three dependent variables, indicating that the number of new business starts in these sectors is positively related to the presence of new business starts in neighboring blocks. Interestingly, service and retail new starts exhibit substantially greater spillover effects than knowledge new starts. More importantly, the inclusion of these variables controls for the impact of these spillovers on the variables of interest, DPOSTIMP and TRPOSTIMP.

These results are also robust to the definition of the treatment area boundary: AITS models run using alternative definitions of the treatment area - the $1 / 4,1 / 2$, and 1-mile boundaries ${ }^{4}$ coupled with the same 7.5-mile control area - show similar signs and patterns of significance, with some interesting spatial variation in coefficient magnitude. While these additional treatment and control area combinations do not demonstrate the ideal minimization of difference in preintervention trend (described above), they do provide some insight into the spatial extent of light rail impacts on new business starts. Figure 4 shows the statistically-significant incidence rate ratio percent change values for DPOSTIMP for each of the three dependent variables of interest in these alternative models. Interestingly, the impact of the light rail on the absolute number of new business starts is greatest within the $1 / 4$ mile boundary and decreases with distance from the stations. This diminishing spatial gradient is greatest for retail new starts least significant for service new starts.

\footnotetext{
${ }^{4}$ Full regression results for these models available upon request.
} 
[INSERT FIGURE 4]

\section{Discussion and Conclusion}

The results of this analysis speak to three important factors regarding the planning and construction of the Valley Metro light rail system in Phoenix and associated TOD that can be applied in other fast-growing metropolitan areas with new fixed rail transit systems. First, when compared to automobile-adjacent areas, proximity to the light rail significantly increases new business starts in the three industries of interest: retail, services, and knowledge. Even when controlling for a variety of factors - including location in a downtown business district adjacency to light rail stations is worth about $88 \%$ additional new starts in the knowledge sector, $40 \%$ new starts in the service sector, and $28 \%$ new starts in the retail sector over the time that the line has been open. This suggests that TOD planning efforts are economically worthwhile, given the fact that new businesses have taken advantage of economic benefits in station-adjacent blocks. This provides some evidence to support the use of light rail systems as new business catalyzation or revitalization tools, even in historically auto-centric regions.

However, the second key finding of this study is that the automobile-oriented development areas have been making up the gap in new business creation at the rate of $8 \%, 6 \%$, and $7 \%$ per year (in the knowledge, service, and retail sectors, respectively) since the light rail opened. This interesting finding follows the pattern of rail system impact discussed in previous research. There appears to be a much higher anticipated value or perceived benefit to a new rail transit system that catalyzes economic activity leading up to, or shortly following, its opening, which then dissipates as the 'novelty factor' wears off (Mohammad et al., 2013). There is not enough data yet to know whether, in the long run, the diminishing returns (in terms of new business starts) from the light rail might eventually erase the absolute advantage it conferred. 
Certainly, as the system stabilizes, its agglomeration and visibility benefits may still foster a significantly higher number of new business starts than would have otherwise been the case, but simply at a lower level than was observed immediately after the line opened. This effect is observed in relation to the auto-oriented control areas, and is not likely to indicate the ultimate demise of the economic well-being of the station areas.

The idea that perception is bigger than reality when it comes to the economic development potential of fixed-route transit systems is particularly illuminating for the urban transportation planning community, raising the obvious question of how to prevent or mitigate these drop-offs in new business activity. One solution suggested by the case of Phoenix - where the system serves a relatively small proportion of regional travel - is to ensure that new transit systems are truly competitive with other modes from a transportation service standpoint. Ultimately, any economic benefits stem from the system's usefulness as a mode of transportation, which requires a high quality of service, dependability, speed, low cost, and a wide range of potential destinations. If the rail system does not compete well in these facets, then it is likely that any economic benefits observed at its construction - investments dependent on the pure novelty of the mode rather than its practical benefit - will diminish over time. Thus planners concerned in maintaining the initial economic benefits from the system's construction must work to ensure increasing service quality and usefulness of the line.

Finally, the third key result of this paper is that impacts to new business creation diminish with distance from the stations, but are still significant for all three of the studied types at 1 mile (network distance) from stations. In addition, the three types of businesses are impacted differently by distance from light rail stations: the benefits drop most quickly with distance for retail businesses (21\%), while knowledge (12\%) and service (0\%) businesses do not drop as 
quickly. Taken together, these results suggest that TOD schemes may be most effective at fostering business formation in the knowledge sector, and that the closer they are targeted to the station, the more impactful they will be. This spatially-explicit information is also useful to station-area planners and entrepreneurs concerned with capitalizing on the economic benefits of the new system, as the results show that locations within $1 / 4$-mile of stations experience greater levels of new business investment. Planners looking to target station areas for special TOD zoning districts or other development-supportive policies (e.g., increased density) should look for opportunities as close to stations as possible and transition on a gradient outward, as far away as a mile.

Of course, there are several limitations to the approach used in this study: it does not directly consider the individual impacts of zoning, construction, and transit service on business formation or trends across different metropolitan areas. Also, while this study measures the general social context for light rail planning in Phoenix, it does not provide a holistic account the multifarious ways in which social conditions influence the relationship between transit system development and new business activity. In addition, the statistical approach employed in this paper inevitably relies on a set of specific assumptions that simplify economic decision-making behavior and offer only quantitative results. Future extensions of this work could control for the impact of land use regulations, provide comparisons with other regions investing in new transit systems, elaborate on the social context for regional economic development, and provide additional explanation and 'ground-truthing' of these results, perhaps through a follow-up qualitative analysis of station-area land use characteristics and entrepreneurs. Finally, a useful theoretical extension of this paper could test the explicit impact of transit on fostering business and social ties and/or creative class workers, as suggested by the paper's conceptual framework. 
Methodologically, this paper provides a new application of the quasi-experimental AITS approach and neighborhood-scale spatial analysis, both of which have been missing from previous analyses of the economic impact of public transportation systems. The adjustedinterrupted nature of the analysis provides significant clarity on the direction of the relationship that is not possible in cross-sectional analyses. In addition, by employing point-level NETS data and explicitly considering a range of spatial scales, this paper develops a robust method that examines transit impacts to new business formation in fine spatial detail.

As for theoretical implications, the results of this paper confirm that there are indeed economic benefits for new firms due specifically to the construction of light rail transit and TOD. This is an important addition to existing knowledge about the economic impacts of transit systems, because it shows that transit stations can, in fact, provide micro-agglomeration benefits to businesses, and that these benefits vary by sector and diminish with distance. The long-term effects of these benefits, the specific mechanisms through which they operate, and their effect on larger economic factors like productivity, innovation, and economic diversification remain to be studied. However, this paper provides strong evidence for the idea that transit systems foster business development in adjacent neighborhoods. This information can be used by planners, policy makers, and entrepreneurs to maximize economic benefits around transit and to create sustainable transit-oriented economic development. 


\section{References}

Acs ZJ and DB Audretsch (2003) Innovation and Technological Change. In Acs ZJ and DB Audretsch (eds) Handbook of Entrepreneurship Research, pp. 55-79.

Agostini CA and G Palmucci (2008) The Anticipated Capitalization Effect of a New Metro Line on Housing Prices. Fiscal Studies 29: 233-56.

American Planning Association (APA) (2014) Investing in Place: Two Generations' View on the Future of Communities. American Planning Association. Retrieved from: https://www.planning.org/policy/polls/investing/pdf/pollinvestingreport.pdf. Accessed: October 2015.

American Public Transit Association (APTA) (1994) Glossary of Transit Terminology. American Public Transit Association. Retrieved from: http://www.apta.com/resources/reportsandpublications/Documents/Transit_Glossary_199 4.pdf. Accesses: June 2017.

Asheim BT, SH Lawton, and C Oughton (2011) Regional innovation systems: theory, empirics and policy. Regional Studies 45(7): 875-891.

Bolin B, S Grineski and T Collins (2005) The Geography of Despair: Environmental Racism and the Making of South Phoenix, Arizona, USA. Human Ecology Review 12(2): 156-168.

Bollinger CR and KR Ihlanfeldt (1997) The Impact of Rapid Rail Transit on Economic Development: The Case of Atlanta's MARTA. Journal of Urban Economics 42: 179204.

Bradley University (2008) Choosing a Retail Location. Turner Center for Entrepreneurship. Retrieved from: 
http://www.bradley.edu/academic/colleges/fcba/centers/turner/established/resources/locat ion.dot. Accessed: November 2015.

Brueckner JK (2000) Urban Sprawl: Diagnosis and remedies. International Regional Science Review 23(2): 160-171.

Calthorpe P (1993) The Next American Metropolis: Ecology, Community, and the American Dream. New York: Princeton Architectural Press.

Carree MA and AR Thurik (2003) The Impact of Entrepreneurship on Economic Growth. In Acs ZJ and DB Audretsch (eds) Handbook of Entrepreneurship Research, pp. 437-471.

Cervero R and J Landis (1997) Twenty Years of the Bay Area Rapid Transit System: Land Use and Development Impacts. Transportation Research Part A 41(4): 309-333.

Cervero R (2004) Effects of Light and Commuter Rail Transit on Land Prices: Experiences in San Diego County. Journal of the Transportation Research Forum 43(1): 121-38.

Chatman DG and RB Noland (2011) Do Public Transport Improvements Increase Agglomeration Economies? A Review of Literature and an Agenda for Research. Transport Reviews 31(6): 725-742.

Chatman DG (2013) Does TOD Need the T? Journal of the American Planning Association 79(1): 17-31.

Chatman DG, RB Noland, and NJ Klein (2016) Firm births, access to transit, and agglomeration in Portland, Oregon, and Dallas, Texas. Transportation Research Record: Journal of the Transportation Research Board 2598: 1-10.

Curtis C, JL Renne, and L Bertolini (2009) Transit Oriented Development: Making it Happen. Burlington: Ashgate. 
Darden JT, M Rahbar, L Jezierski, M Li, and E Velie (2010) The measurement of neighborhood socioeconomic characteristics and black and white residential segregation in metropolitan detroit: Implications for the study of social disparities in health. Annals of the Association of American Geographers 100(1): 137-158.

Darden JT and SM Kamel (2000) Black Residential Segregation in the City and Suburbs of Detroit: Does Socioeconomic Status Matter? Journal of Urban Affairs 22(1): 1-13.

Damm D, SR Lerman, E Lerner-Lam and J. Young (1980) Response of Urban Real Estate Values in Anticipation of the Washington Metro. Journal of Transport Economics and Policy 14(3): 315-36.

De Bruijn H and W Veeneman (2009) Decision-making for light rail. Transportation Research Part A: Policy and Practice 43(4): 349-359.

Dittmar H and G Ohland (2004) The New Transit Town: Best Practices in Transit-Oriented Development. Washington: Island Press.

Downtown Phoenix, Inc. (2015) Downtown Core. Retrieved from: http://dtphx.org/live/neighborhoods/downtown-core/. Accessed 2015.

Economist (2017) Snow belt to sun belt: Migration southward and westward is picking up again. Why Chicagoans are leaving in droves. The Economist. Retrieved from: http://www.economist.com/news/united-states/21721215-why-chicagoans-are-leavingdroves-migration-southward-and-westward-picking-up-again?frsc=dg\%7Cc. Accessed 2017.

ESRI Business Analyst (2014) ESRI Business Locations and Business Summary [Data file]. Retrieved from: http://www.esri.com/data/esri_data/business-overview/business. Accessed 2015. 
Ewing R (1997) Is Los Angeles-style Sprawl Desirable? Journal of the American Planning Association 63(1): 107-126.

Faraway JJ (2006) Extending the Linear Model with R: Generalized Linear, Mixed Effects and Nonparamteric Regression Models. New York: Chapman \& Hall.

Florida R (2002) The Rise of the Creative Class: And How It's Transforming Work, Leisure, Community, and Everyday Life. New York: Basic Books.

Florida R (2004) Cities and the Creative Class. New York: Routledge.

Freemark Y (2014) Have U.S. Light Rail Systems Been Worth the Investment? Citylab. Retrieved from: http://www.citylab.com/commute/2014/04/have-us-light-rail-systemsbeen-worth-investment/8838/. Accessed 2015.

Frenken K, F Van Oort and T Verburg (2007) Related Variety, Unrelated Variety and Regional Economic Growth. Regional Studies 41(5): 685-697.

Galster G, K Temkin, C Walker and N Sawyer (2004) Measuring the Impacts of Community Development Initiatives: A New Application of the Adjusted Interrupted Time-Series Method. Evaluation Review 28(6): 502-538.

Giuliano G (2004) Land Use Impacts of Transportation Investments: Highway and Transit. In: Hanson S and G Guiliano (eds) The Geography of Urban Transportation. New York: Guilford Press, pp. 237-273.

Golub A, S Guhathakurta and B Sollapuram (2012) Spatial and Temporal Capitalization Effects of Light Rail in Phoenix: From Conception, Planning, and Construction to Operation. Journal of Planning Education and Research 32(4): 415-429.

Gordon IR and P McCann (2000) Industrial Clusters: Complexes, Agglomeration and/or Social Networks? Urban Studies 37(3): 513-532. 
Guerra E, R Cervero, and D Tischler (2011) The Half-Mile Circle: Does It Best Represent Transit Station Catchments? Working Paper: Institute of Transportation Studies, University of California, Berkeley. Retrieved from: http://www.its.berkeley.edu/sites/default/files/publications/UCB/2011/VWP/UCB-ITSVWP-2011-5.pdf. Accessed: 2016.

Hammann E, A Habisch and H Pechlaner (2009) Values that Create Value: Socially Responsible Business Practices in SMEs - Empirical Evidence from German Companies. Business Ethics: A European Review 18(1): 37-51.

Hyra D (2015) The Back-to-the-City Movement: Neighbourhood Redevelopment and Processes of Political and Cultural Displacement. Urban Studies 52(10): 1753-1773.

Jacobs J (1961) Death and Life of Great American Cities. New York: Random House. Jacobs, J (1967) The Economy of Cities. New York: Random House.

Knapp G, JC Ding and LD Hopkins (2001) Do Plans Matter? The Effects of Light Rail Plans on Land Values in Station Areas. Journal of Planning Education and Research 21(1): 32-39. Landis J, S Guhathakurta and M Zhang (1994) Capitalization of Transit Investments into SingleFamily Home Prices: A Comparative Analysis Of Five California Rail Transit Systems. The University of California Transportation Center 246: 1-38. Retrieved from: http://www.uctc.net/papers/246.pdf. Accessed 2014.

Mayer H (2011) Entrepreneurship and Innovation in Second Tier Regions. Northampton, MA: Edward Elgar.

Mohammad S, D Graham, P Melo and R Anderson (2013) A Meta-Analysis of the Impact of Rail Projects on Land and Property Values. Transportation Research Part A 50: 158-170. 
National Historic Geographic Information System (1990) U.S. Geographic Summary Data and Boundary Files - 1990 Metropolitan Statistical Area Population [Data file]. Retrieved from: https://www.nhgis.org/. Accessed 2017.

Nelson M (2005). Rethinking agglomeration economies and the role of the central city. Journal of Planning Education and Research 24(3): 331-341.

Newman and Kenworthy. (2013) Urban Sustainability in an Australian Context. Urban Sustainability: 227-254.

Orlitzky M, FL Schmidt and SL Rynes (2003) Corporate Social and Financial Performance: A Meta-Analysis. Organization Studies 24(3): 403-441.

Pagliara F and E Papa (2011) Urban Rail Systems Investments: An Analysis of the Impacts on Property Values and Residents' Location. Journal of Transport Geography 19: 200-211. Quinn B (2006) Transit-Oriented Development: Lessons from California. Built Environment 32(3): 311-322.

Resource Systems Group (RSG) (2014) Who's on Board 2014: Mobility Attitudes Survey. Prepared for TransitCenter. Retrieved from: http://transitcenter.org/wpcontent/uploads/2014/08/WhosOnBoard2014-ForWeb.pdf. Accessed: November 2015.

Robinson KL, W Dassie, and RD Christy (2004) Entrepreneurship and small business development as a rural development strategy. Southern Rural Sociology 20 (2), 1-23.

Rodriguez G (2007) Chapter 4: Poisson Models for Count Data. Lecture Notes on Generalized Linear Models. Retrieved from: http://data.princeton.edu/wws509/notes/c4.pdf. Accessed: November 2015.

Rosenthal SS and WC Strange (2003) Geography, Industrial Organization, and Agglomeration. Center for Policy Research, Paper 107. 
Saxenian A (1994) Regional Advantage: Culture and Competition in Silicon Valley and Route 128. Cambridge: Harvard University Press.

Schuetz J (2014) Do Rail Transit Stations Encourage Neighborhood Retail Activity? Urban Studies. DOI: 10.1177/0042098014549128. Accessed 2014.

Song Y, K Lee, WP Anderson, and TR Lakshmanan (2012) Industrial agglomeration and transport accessibility in metropolitan Seoul. Journal of Geographical Systems 14(3): $299-318$.

Stam E (2007) Why Butterflies Don't Leave: Locational Behavior of Entrepreneurial Firms. Economic Geography 83(1): 27-50.

Storper M and AJ Venables (2004) Buzz: Face-to-Face Contact and the Urban Economy. Journal of Economic Geography 4(4): 351-370.

Sturtevant LA and YJ Jung (2011) Are We Moving Back to the City? Examining Residential Mobility in the Washington, DC Metropolitan Area. Growth and Change 42(1): 48-71.

Tranel M and LB Handlin (2006) Metromorphosis: Documenting Change. Journal of Urban Affairs 28(2): 151-167.

UCLA (2007) R Data Analysis Examples: Poisson Regression. UCLA: Statistical Consulting Group. Retrieved from: http://www.ats.ucla.edu/stat/r/dae/poissonreg.htm. Accessed: November 2015.

United States Census Bureau (2015) Census TIGER/Line Road Shapefile - Maricopa County [Data file]. Retrieved from: https://www.census.gov/geo/maps-data/data/tiger-line.html. Accessed 2016.

United States Census Bureau (2016) Annual Estimates of the Resident Population: April 1, 2010 to July 1, 2016 [Data file]. Retrieved from https://factfinder.census.gov. Accessed 2017. 
Urban Land Institute (ULI) (2015) America in 2015: A ULI Survey of Views on Housing, Transportation, and Community. Urban Land Institute. Retrieved from: http://uli.org/wpcontent/uploads/ULI-Documents/America-in-2015.pdf. Accessed: November 2015.

Vessali KV (1996) Land Use Impacts of Rapid Transit: A Review of the Empirical Literature. Berkeley Planning Journal 11(1): 72-105.

Walls and Associates (2012) National Establishment Time Series - Maricopa County [Data file]. Ward MD and KS Gleditsch (2008) Spatial Regression Models. Thousand Oaks, California: Sage Publications.

Weinberger RR (2001) Light Rail Proximity: Benefit or Detriment in the Case Of Santa Clara County, California? Transportation Research Record 1747: 104-11.

Weinstein B and TL Clower (2003) DART Light Rail's Effect on Taxable Property Valuations and Transit-Oriented Development. University of North Texas. Retrieved from: http://www.valleymetro.org/images/uploads/general_publications/2003_DART_Study.pd f. Accessed 2014.

Weissmann J (2012) Why Don't Young Americans Buy Cars? The Atlantic. Retrieved from: http://www.theatlantic.com/business/archive/2012/03/why-dont-young-americans-buycars/255001/. Accessed: October 2015.

Wennekers S, A Van Stel, R Thurik and P Reynolds (2005) Nascent Entrepreneurship and the Level of Economic Development. Small Business Economics 24: 293-309.

Wennekers S and R Thurik (1999) Linking Entrepreneurship and Economic Growth. Small Business Economics 13(1): 27-55.

Zhao F, LF Chow, MT Li, A Gan, and I Ubaka. (2003) Forecasting transit walk accessibility: Regression model alternative to buffer. Transportation Research Record 1835: 34-41. 


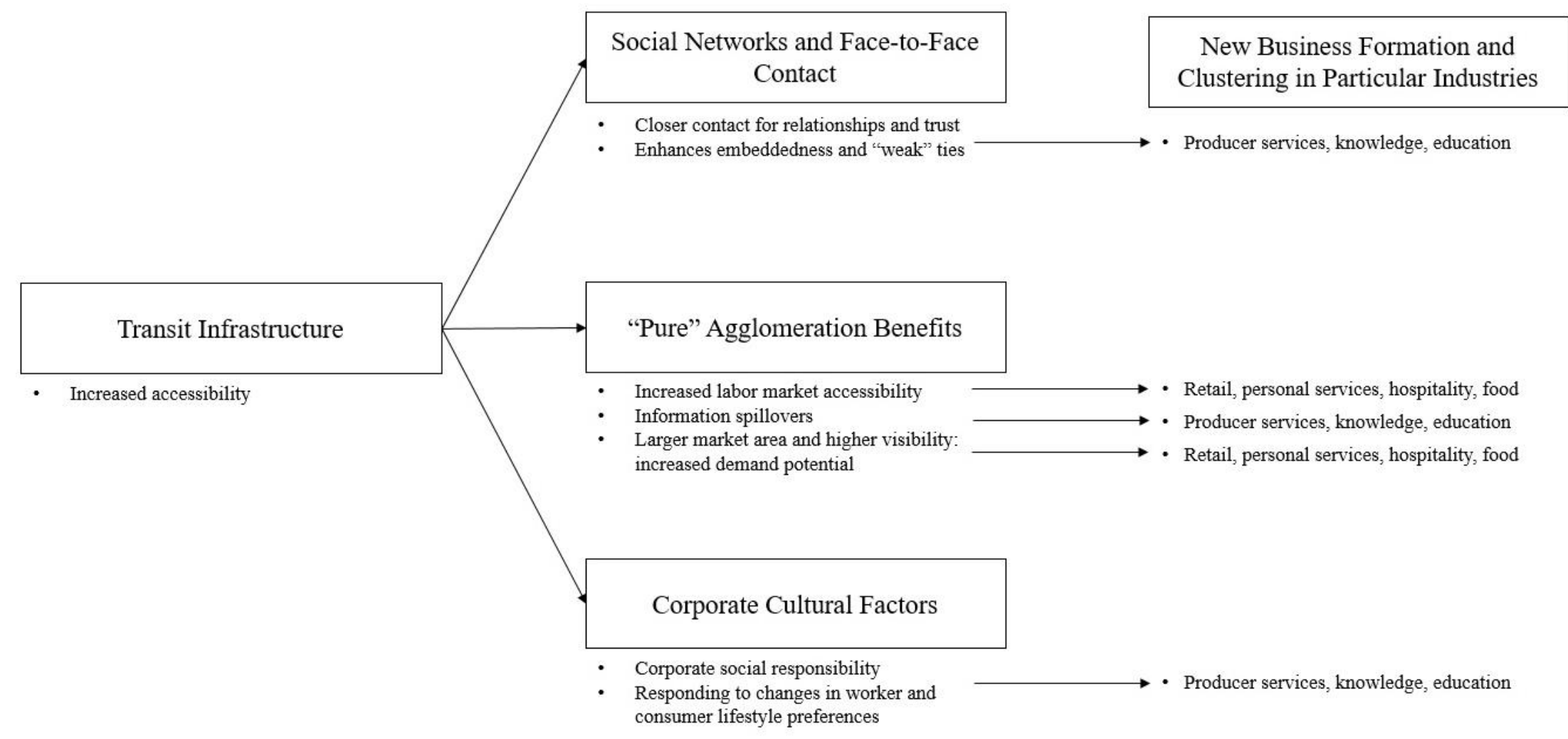

Figure 1. Conceptual framework showing how transit infrastructure influences individual business location decisions and clustering. 


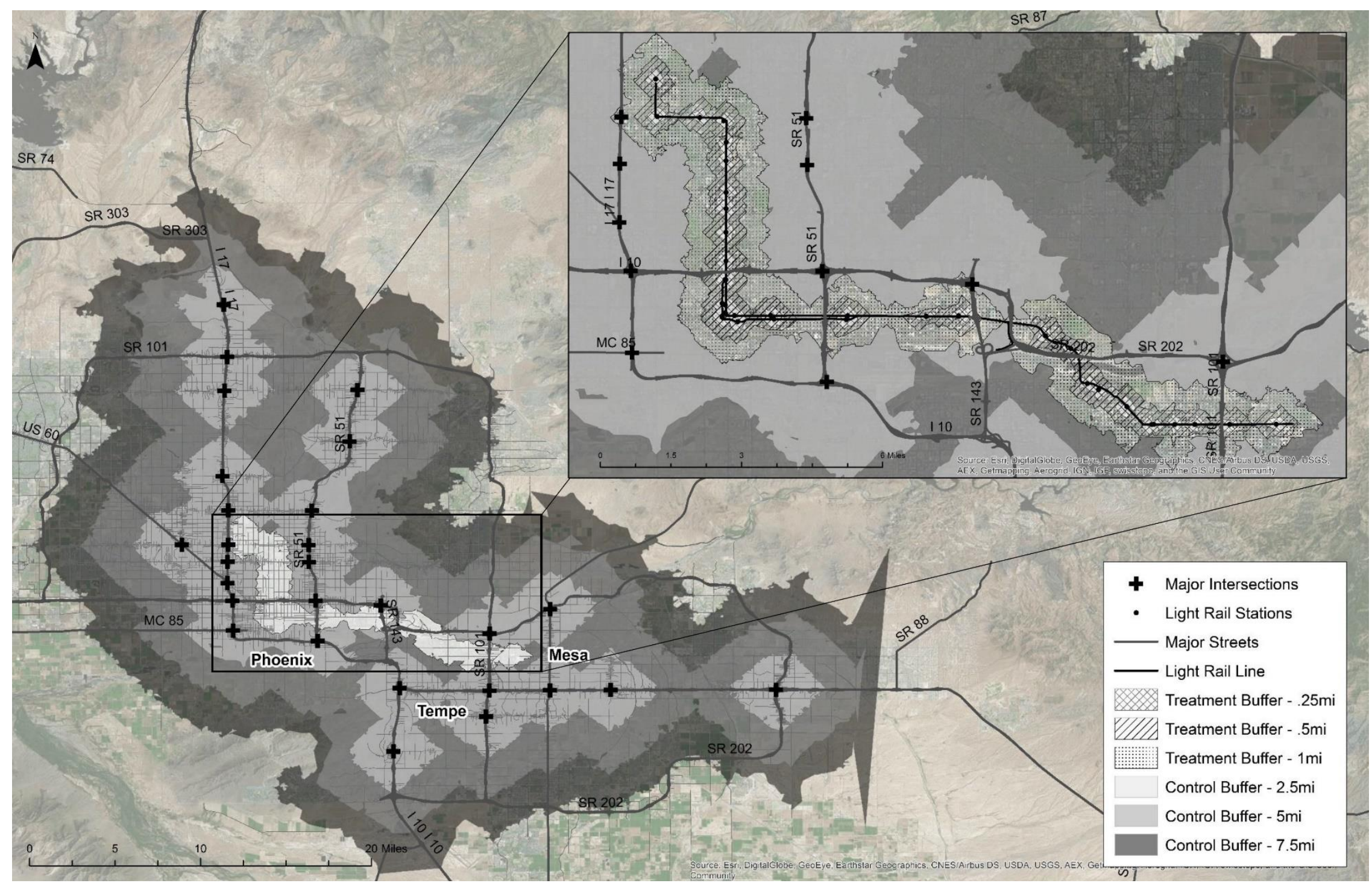

Figure 2. Map showing six treatment and control areas considered for analysis. 


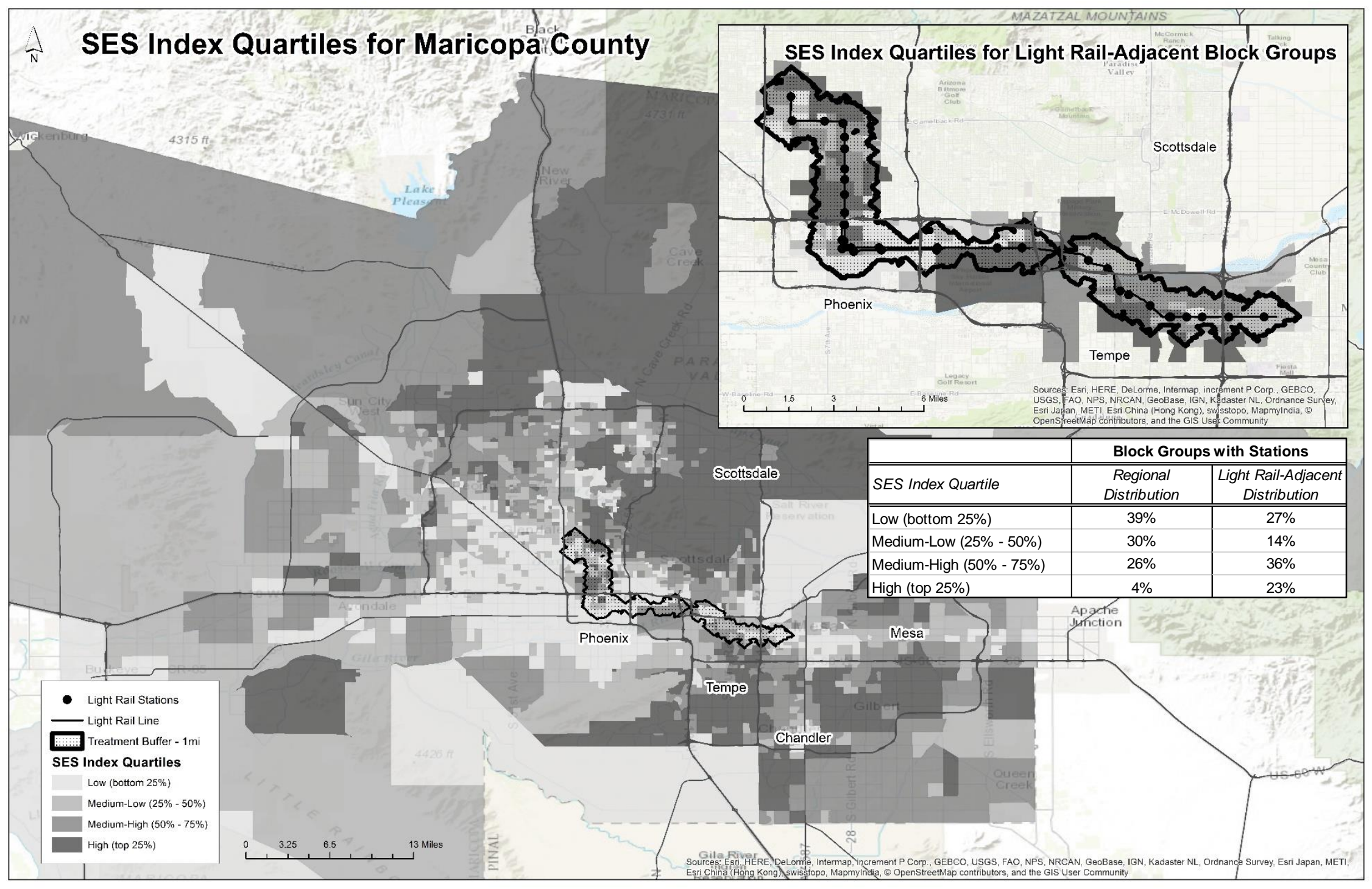

Figure 3. Map showing SES index score (in 2000) distributions for Maricopa County and light rail-adjacent block groups. 


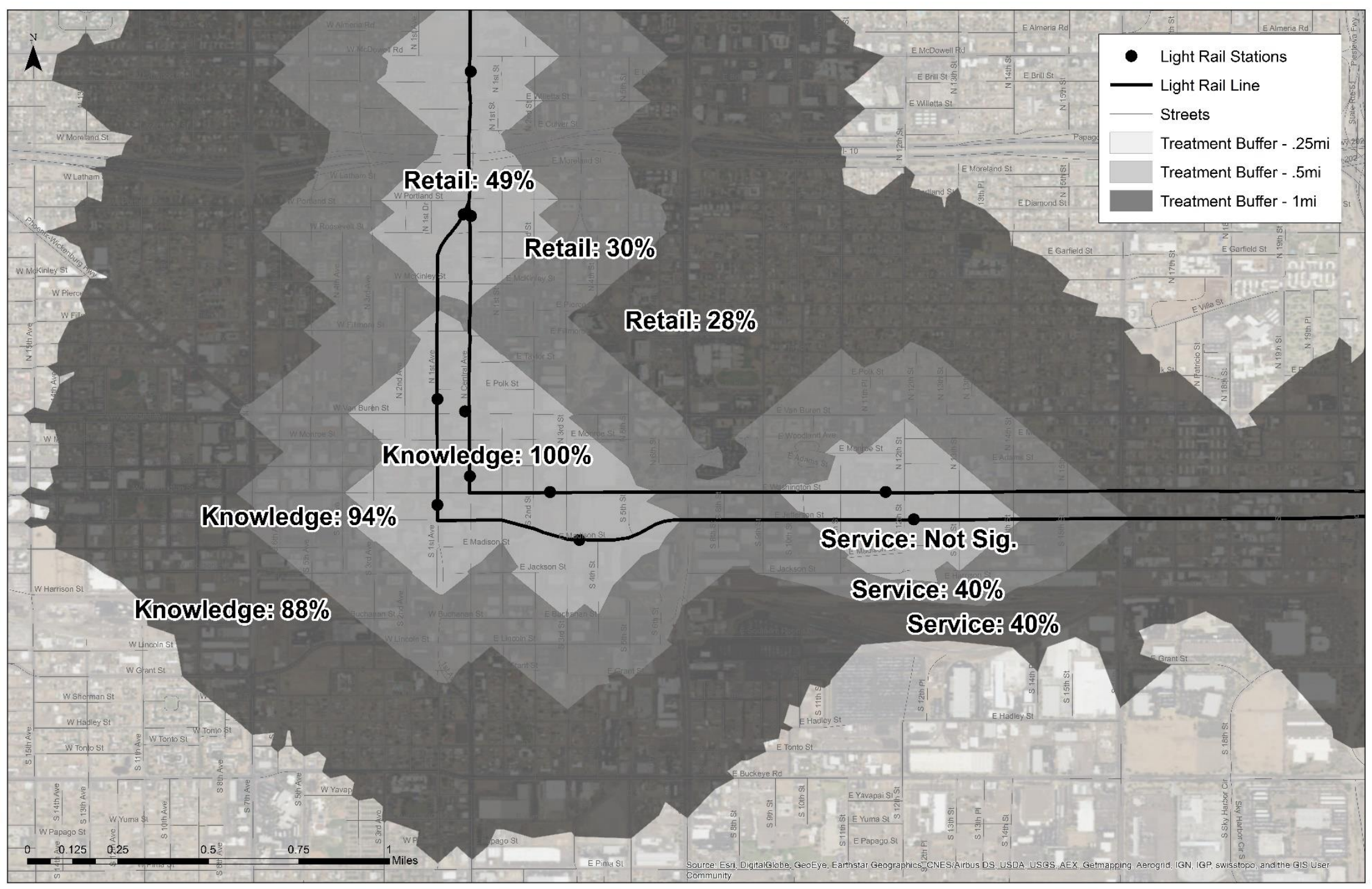

Figure 4. Map showing percent change incidence rate ratios for DPOSTIMP variable for varying defintions of the treatment boundary $-1 / 4,1 / 2$, and 1 mile - in central Phoenix. 
Table 1. Poisson AITS model results and incidence rate ratios (IRR) for three dependent variables of interest.

\begin{tabular}{|c|c|c|c|c|c|c|c|c|c|c|c|c|}
\hline \multirow[t]{2}{*}{ Dependent variable } & \multicolumn{4}{|c|}{ \# Retail New Starts } & \multicolumn{4}{|c|}{ \# Knowledge New Starts } & \multicolumn{4}{|c|}{ \# Service New Starts } \\
\hline & Coef. & Std. Err. & $I R R$ & $1-I R R$ & Coef. & Std. Err. & $I R R$ & $1-I R R$ & Coef. & Std. Err. & $I R R$ & $1-I R R$ \\
\hline \multicolumn{13}{|l|}{ AITS variables $(\alpha)$} \\
\hline DIMP & 0.535 & 0.053 & 1.707 & $71 \%$ & 1.512 & 0.033 & 4.537 & $354 \%$ & 0.753 & 0.049 & 2.124 & $112 \%$ \\
\hline DPOSTIMP & 0.250 & 0.093 & 1.284 & $28 \%$ & 0.630 & 0.046 & 1.879 & $88 \%$ & 0.335 & 0.073 & 1.398 & $40 \%$ \\
\hline TRIMP & -0.018 & 0.004 & 0.982 & $-2 \%$ & -0.065 & 0.003 & 0.937 & $-6 \%$ & -0.019 & 0.004 & 0.981 & $-2 \%$ \\
\hline TRPOSTIMP & -0.073 & 0.026 & 0.929 & $-7 \%$ & -0.079 & 0.013 & 0.924 & $-8 \%$ & -0.058 & 0.019 & 0.943 & $-6 \%$ \\
\hline$T R A L L$ & 0.064 & 0.001 & 1.067 & $7 \%$ & 0.127 & 0.001 & 1.135 & $14 \%$ & 0.075 & 0.001 & 1.078 & $8 \%$ \\
\hline TRPOSTALL & -0.273 & 0.005 & 0.761 & $-24 \%$ & -0.304 & 0.003 & 0.738 & $-26 \%$ & -0.224 & 0.004 & 0.799 & $-20 \%$ \\
\hline \multicolumn{13}{|l|}{ Covariates $(x)$} \\
\hline$\overline{A E V L A G^{l}}$ & 0.839 & 0.010 & 2.315 & $131 \%$ & 0.317 & 0.002 & 1.373 & $37 \%$ & 0.964 & 0.010 & 2.622 & $162 \%$ \\
\hline$B U S \_D$ & 1.381 & 0.029 & 3.978 & $298 \%$ & 1.365 & 0.018 & 3.916 & $292 \%$ & 1.303 & 0.027 & 3.682 & $268 \%$ \\
\hline$I N T \_D E N$ & -0.085 & 0.008 & 0.918 & $-8 \%$ & -0.023 & 0.004 & 0.978 & $-2 \%$ & -0.085 & 0.007 & 0.919 & $-8 \%$ \\
\hline$B L O C K \_L$ & 0.000 & 0.000 & 1.000 & $-0.01 \%$ & 0.000 & 0.000 & 1.000 & $-0.01 \%$ & -0.0001 & 0.000 & 1.000 & $-0.01 \%$ \\
\hline$B L K$ & 0.619 & 0.155 & 1.857 & $86 \%$ & -0.398 & 0.125 & 0.671 & $-33 \%$ & 0.876 & 0.131 & 2.401 & $140 \%$ \\
\hline$M I D$ & 0.375 & 0.030 & 1.455 & $46 \%$ & 1.251 & 0.017 & 3.494 & $249 \%$ & 0.815 & 0.026 & 2.260 & $126 \%$ \\
\hline$E M P D$ & 0.001 & 0.000 & 1.001 & $0.1 \%$ & 0.001 & 0.000 & 1.001 & $0.1 \%$ & 0.001 & 0.000 & 1.001 & $0.1 \%$ \\
\hline RETP & 2.045 & 0.038 & 7.726 & $673 \%$ & 0.304 & 0.040 & 1.355 & $36 \%$ & 1.003 & 0.048 & 2.726 & $173 \%$ \\
\hline$M A N P$ & 0.234 & 0.108 & 1.264 & $26 \%$ & -0.243 & 0.078 & 0.784 & $-22 \%$ & & & & \\
\hline$I N F P$ & 0.729 & 0.138 & 2.073 & $107 \%$ & - & - & - & - & 0.354 & 0.139 & 1.424 & $42 \%$ \\
\hline Constant & -5.927 & 0.018 & 0.003 & $-100 \%$ & -6.141 & 0.014 & 0.002 & $-100 \%$ & -6.034 & 0.018 & 0.002 & $-100 \%$ \\
\hline \multicolumn{13}{|l|}{ Offset $(\delta)$} \\
\hline ACRES & 1 & & & & 1 & & & & 1 & & & \\
\hline$N$ & 1040250 & & & & 1040250 & & & & 1040250 & & & \\
\hline Psuedo- $R^{2}$ & 0.085 & & & & 0.126 & & & & 0.089 & & & \\
\hline
\end{tabular}

All results reported here are significant at the .05 level $(\mathrm{p} \leq .05)$.

INFP not included in model for knowledge new starts due to collinearity. 
Appendix A.1. Table showing the pre-intervention (1990-2008) linear equations for the average number of new businesses per block per year.

\begin{tabular}{|c|c|c|c|c|c|c|}
\hline \multirow[b]{2}{*}{ Type of New Business } & \multicolumn{3}{|c|}{ Possible Treatment Areas } & \multicolumn{3}{|c|}{ Possible Control Areas } \\
\hline & $.25 m i$ & $.5 m i$ & $1 m i$ & $2.5 m i$ & $5 m i$ & $7.5 m i$ \\
\hline Retail (NAICS 44-45) & $0.0032 x-6.2865$ & $0.0022 x-4.2392$ & $0.002 x-3.8632$ & $0.0017 x-3.4357$ & $0.0017 x-3.3635$ & $0.0017 x-3.3942$ \\
\hline Services (NAICS $72 \& 81$ ) & $0.0061 x-11.953$ & $0.0043 x-8.4022$ & $0.0031 x-6.159$ & $0.0018 x-3.632$ & $0.0019 x-3.6757$ & $0.0019 x-3.839$ \\
\hline Knowledge (NAICS 51-52 \& 54-55) & $0.0338 x-66.986$ & $0.0135 x-26.671$ & $0.0095 x-18.82$ & $0.0065 x-12.876$ & $0.0064 x-12.684$ & $0.0066 x-13.172$ \\
\hline
\end{tabular}

Appendix A.2. Table showing differences in pre-intervention (1990-2008) linear slope coefficients in the average number of new businesses per block per year for nine possible boundary combinations. The boundary combinations with the lowest value - and thus most similar preintervention trend - are highlighted.

\begin{tabular}{l|c|c|c|c|c|c|c|c|c} 
& \multicolumn{7}{|c|}{ Possible Boundary Combinations (Treatment/Control Areas) } \\
\hline \hline Type of New Business & $.25 \mathrm{mi} /$ & $.25 \mathrm{mi} /$ & $.25 \mathrm{mi} /$ & $.5 \mathrm{mi} /$ & $.5 \mathrm{mi} /$ & $.5 \mathrm{mi} /$ & $\begin{array}{c}1 \mathrm{mi} / \\
2.5 \mathrm{mi}\end{array}$ & $\begin{array}{c}1 \mathrm{mi} / \\
5 \mathrm{mi}\end{array}$ & $\begin{array}{c}1 \mathrm{mi} / \\
7.5 \mathrm{mi}\end{array}$ \\
\hline \hline Retail (NAICS 44-45) & $2.5 \mathrm{mi}$ & $5 \mathrm{mi}$ & $7.5 \mathrm{mi}$ & $2.5 \mathrm{mi}$ & $5 \mathrm{mi}$ & $7.5 \mathrm{mi}$ & $2.5 \mathrm{~m}$ \\
Services (NAICS 72 \& 81) & 0.0015 & 0.0015 & 0.0015 & 0.0005 & 0.0005 & 0.0005 & 0.0003 & 0.0003 & 0.0003 \\
Knowledge (NAICS 51-52 \& 54-55) & 0.0043 & 0.0042 & 0.0042 & 0.0025 & 0.0024 & 0.0024 & 0.0013 & 0.0012 & 0.0012 \\
\hline \hline
\end{tabular}


Appendix B. Graphs showing the pre-intervention (1990-2008) linear trends and equations for the average number of new businesses per block per year for the chosen (most-similar) boundary combination: 1 mile / 7.5 mile.
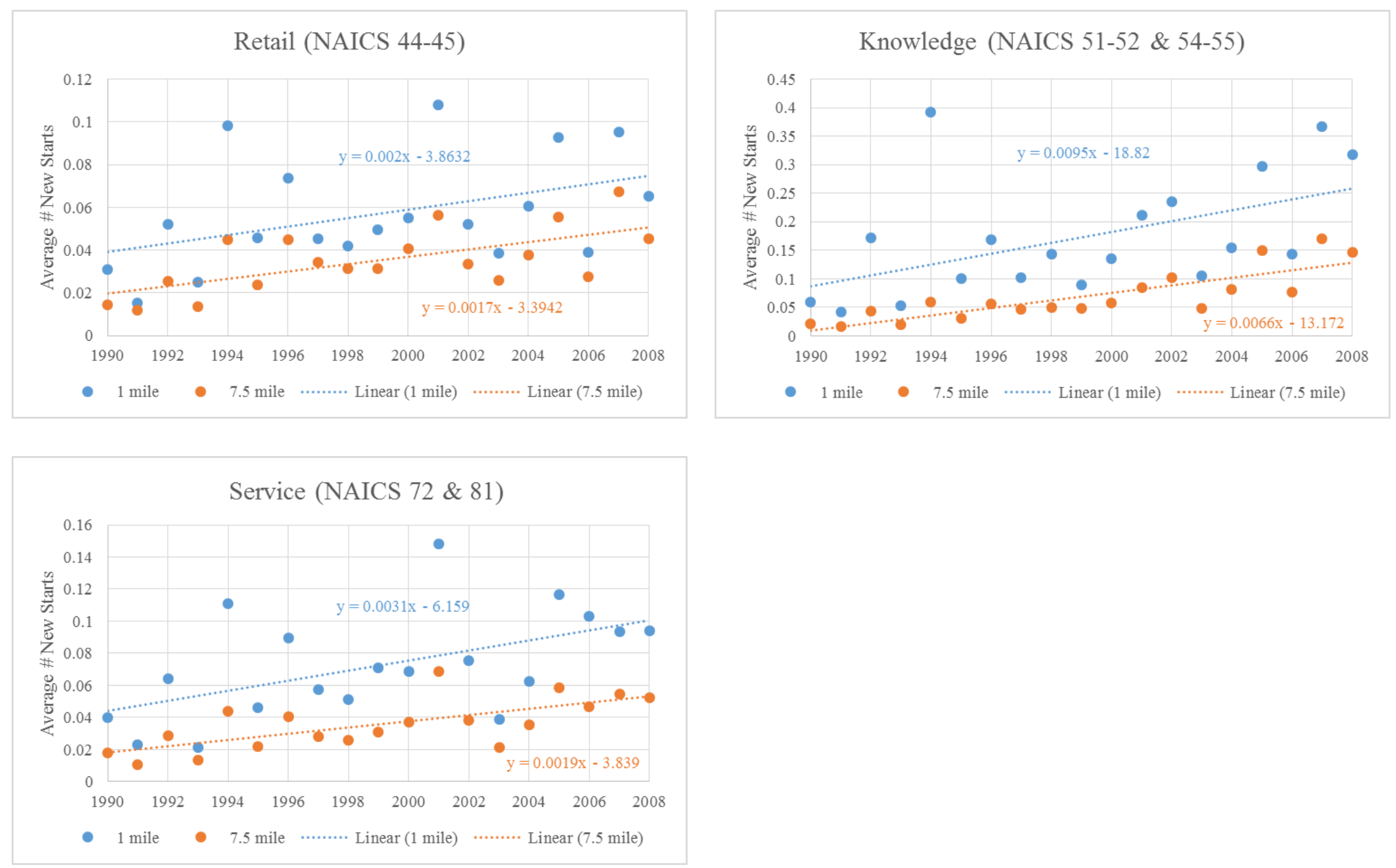
Appendix C. Table describing the independent variables used in the final AITS model.

\begin{tabular}{|c|c|c|c|c|}
\hline Category & Name & Description & Years Available & Source \\
\hline \multicolumn{5}{|l|}{ AITS variables $(\alpha)$} \\
\hline Variables of interest & $\begin{array}{l}\text { DPOSTIMP } \\
\text { TRPOSTIMP }\end{array}$ & $\begin{array}{l}\text { Dummy for post-intervention observations in } \\
\text { treatment area } \\
\text { Trend for post-intervention observations in } \\
\text { treatment area (e.g., } 1=2009,2=2010 \text {, etc.) }\end{array}$ & $\begin{array}{l}1990-2014 \\
1990-2014\end{array}$ & $\begin{array}{l}\text { Author's creation } \\
\text { Author's creation }\end{array}$ \\
\hline $\begin{array}{l}\text { Pre-intervention absolute } \\
\text { difference and trend } \\
\text { controls }\end{array}$ & $\begin{array}{l}\text { DIMP } \\
\text { TRIMP }\end{array}$ & $\begin{array}{l}\text { Dummy for all observations in treatment area } \\
\text { Trend for all observations in treatment area (e.g., } \\
1=1990,2=1991 \text {, etc.) }\end{array}$ & $\begin{array}{l}1990-2014 \\
1990-2014\end{array}$ & $\begin{array}{l}\text { Author's creation } \\
\text { Author's creation }\end{array}$ \\
\hline Overall trend controls & $\begin{array}{l}\text { TRALL } \\
\text { TRPOSTALL }\end{array}$ & $\begin{array}{l}\text { Trend for all observations in both areas } \\
\text { Trend for all post-intervention observations in } \\
\text { both areas }\end{array}$ & $\begin{array}{l}1990-2014 \\
1990-2014\end{array}$ & $\begin{array}{l}\text { Author's creation } \\
\text { Author's creation }\end{array}$ \\
\hline \multicolumn{5}{|l|}{ Exposure $(\delta)$} \\
\hline & ACRES & Size of block in acres & 2010 & Census TIGER/Line shapefiles \\
\hline \multicolumn{5}{|l|}{ Covariates $(x)$} \\
\hline $\begin{array}{l}\text { Overall economic } \\
\text { characteristics: market } \\
\text { size and jobs }\end{array}$ & $\begin{array}{l}P O P \\
E M P D\end{array}$ & $\begin{array}{l}\text { Population } \\
\text { Employment density (per acre) }\end{array}$ & $\begin{array}{l}1990,2000,2010 \\
1990,2000,2010\end{array}$ & $\begin{array}{l}\text { Decennial Census } \\
\text { National Establishment Time Series (NETS) }\end{array}$ \\
\hline Business dynamics & $\begin{array}{l}\text { RETP } \\
\text { MANP } \\
\text { INFP } \\
\text { BUS_D }\end{array}$ & $\begin{array}{l}\% \text { existing retail (NAICS 44-45) businesses } \\
\% \text { existing manufacturing (NAICS } 31-33 \text { ) } \\
\text { businesses } \\
\% \text { existing information (NAICS } 51 \text { ) businesses } \\
\text { Location in a downtown business district }{ }^{2}\end{array}$ & $\begin{array}{l}1990-2014 \\
1990-2014 \\
1990-2014 \\
2015\end{array}$ & $\begin{array}{l}\text { National Establishment Time Series (NETS) } \\
\text { National Establishment Time Series (NETS) } \\
\text { National Establishment Time Series (NETS) } \\
\text { Author's creation }\end{array}$ \\
\hline Built environment & $\begin{array}{l}I N T \_D E N \\
B L O C K \_L\end{array}$ & $\begin{array}{l}\text { Number of street intersections per acre } \\
\text { Block length in meters }\end{array}$ & $\begin{array}{l}2015 \\
2010\end{array}$ & $\begin{array}{l}\text { Census TIGER/Line shapefiles } \\
\text { Census TIGER/Line shapefiles }\end{array}$ \\
\hline Demographics & $\begin{array}{l}B L K \\
M I D\end{array}$ & $\begin{array}{l}\text { Black non-Hispanic population } \% \\
\% \text { population } 19-64\end{array}$ & $\begin{array}{l}1990,2000,2010 \\
1990,2000,2010\end{array}$ & $\begin{array}{l}\text { Decennial Census } \\
\text { Decennial Census }\end{array}$ \\
\hline Spatial Lags ${ }^{3}$ & $\begin{array}{l}\text { AVRETLAG } \\
\text { AVSERVLAG } \\
\text { AVKNOWLAG }\end{array}$ & $\begin{array}{l}\text { Spatial lag of the average value (over the time } \\
\text { period of the entire study) of new retail } \\
\text { businesses } \\
\text { Spatial lag of the average value (over the time } \\
\text { period of the entire study) of new service } \\
\text { businesses } \\
\text { Spatial lag of the average value (over the time } \\
\text { period of the entire study) of new knowledge } \\
\text { businesses }\end{array}$ & $\begin{array}{l}\text { Average: } 1990- \\
2014 \\
\text { Average: } 1990- \\
2014 \\
\text { Average: } 1990- \\
2014\end{array}$ & $\begin{array}{l}\text { Author's creation } \\
\text { Author's creation } \\
\text { Author's creation }\end{array}$ \\
\hline
\end{tabular}


Appendix D. Descriptive statistics for treatment and control areas.

\begin{tabular}{|c|c|c|c|c|c|c|c|c|c|c|}
\hline \multirow[b]{2}{*}{ Variable } & \multicolumn{5}{|c|}{ Blocks in Light Rail Treatment (1-mile) Area } & \multicolumn{5}{|c|}{ Blocks in Automobile Control (7.5-mile) Area } \\
\hline & Obs & Mean & Std. Dev. & Min & $\operatorname{Max}$ & Obs & Mean & Std. Dev. & Min & $\operatorname{Max}$ \\
\hline \multicolumn{11}{|c|}{ Dependent variables } \\
\hline$K N O W$ & 50075 & 0.17 & 1.55 & 0 & 258 & 990175 & 0.08 & 0.53 & 0 & 104 \\
\hline SERVE & 50075 & 0.07 & 0.43 & 0 & 51 & 990175 & 0.04 & 0.30 & 0 & 60 \\
\hline \multicolumn{11}{|c|}{ AITS variables $(\alpha)$} \\
\hline$\overline{D I M P}$ & 50075 & 1 & 0 & 1 & 1 & 990175 & 0 & 0 & 0 & 0 \\
\hline DPOSTIMP & 50075 & 0.28 & 0.45 & 0 & 1 & 990175 & 0 & 0 & 0 & 0 \\
\hline TRIMP & 50075 & 13 & 7.21 & 1 & 25 & 990175 & 0 & 0 & 0 & 0 \\
\hline TRPOSTIMP & 50075 & 1.12 & 2.08 & 0 & 7 & 990175 & 0 & 0 & 0 & 0 \\
\hline$T R A L L$ & 50075 & 13 & 7.21 & 1 & 25 & 990175 & 13 & 7.21 & 1 & 25 \\
\hline TRPOSTALL & 50075 & 1.12 & 2.08 & 0 & 7 & 990175 & 1.12 & 2.08 & 0 & 7 \\
\hline \multicolumn{11}{|c|}{ Covariates $(x)^{i v}$} \\
\hline$A V K N W L A G$ & 50075 & 0.20 & 0.37 & 0 & 3.48 & 990175 & 0.13 & 0.39 & 0 & 22.84 \\
\hline$A V S R V L A G$ & 50075 & 0.09 & 0.11 & 0 & 0.87 & 990175 & 0.06 & 0.14 & 0 & 7.08 \\
\hline$E M P D$ & 6009 & 10.92 & 73.26 & 0 & 2799.91 & 118821 & 1.83 & 30.32 & 0 & 5591.71 \\
\hline RETP & 6009 & $7.0 \%$ & $18.9 \%$ & $0 \%$ & $100 \%$ & 118821 & $4.2 \%$ & $16.1 \%$ & $0 \%$ & $100 \%$ \\
\hline$M A N P$ & 6009 & $2.8 \%$ & $12.5 \%$ & $0 \%$ & $100 \%$ & 118821 & $1.6 \%$ & $10.0 \%$ & $0 \%$ & $100 \%$ \\
\hline$I N F P$ & 6009 & $1.5 \%$ & $8.9 \%$ & $0 \%$ & $100 \%$ & 118821 & $0.7 \%$ & $6.7 \%$ & $0 \%$ & $100 \%$ \\
\hline$B U S \_D$ & 50075 & $7.9 \%$ & $27.0 \%$ & $0 \%$ & $100 \%$ & 990175 & $0.4 \%$ & $6.4 \%$ & $0 \%$ & $100 \%$ \\
\hline$I N T \_D E N$ & 50075 & 1.95 & 4.89 & 0 & 92.67 & 990175 & 2.03 & 11.64 & 0 & 1841.70 \\
\hline$B L O C K \_L$ & 50075 & 2594.50 & 1833.79 & 35.56 & 19862.70 & 990175 & 3094.89 & 3040.69 & 45.18 & 90356.70 \\
\hline$B L K$ & 6009 & $2.9 \%$ & $8.4 \%$ & $0 \%$ & $100 \%$ & 118821 & $1.9 \%$ & $6.6 \%$ & $0 \%$ & $100 \%$ \\
\hline$M I D$ & 6009 & $38.7 \%$ & $35.5 \%$ & $0 \%$ & $100 \%$ & 118821 & $36.0 \%$ & $31.8 \%$ & $0 \%$ & $100 \%$ \\
\hline \multicolumn{11}{|l|}{ Offset $(\delta)$} \\
\hline ACRES & 50075 & 8.38 & 15.58 & 0 & 314.36 & 990175 & 12.82 & 64.71 & 0 & 4855.92 \\
\hline
\end{tabular}


Appendix E. Descriptive statistics for pre- and post-intervention periods for the 1-mile treatment area.

\begin{tabular}{|c|c|c|c|c|c|c|c|c|c|c|}
\hline \multirow[b]{2}{*}{ Variable } & \multicolumn{5}{|c|}{ Pre-Intervention (1990-2007) } & \multicolumn{5}{|c|}{ Post-Intervention (2008-2014) } \\
\hline & Obs & Mean & Std. Dev. & Min & $\operatorname{Max}$ & Obs & Mean & Std. Dev. & Min & $\operatorname{Max}$ \\
\hline \multicolumn{11}{|l|}{ New establishments } \\
\hline Retail new starts & 36054 & 0.057 & 0.34 & 0 & 15 & 14021 & 0.039 & 0.22 & 0 & 5 \\
\hline Knowledge new starts & 36054 & 0.165 & 1.67 & 0 & 258 & 14021 & 0.180 & 1.20 & 0 & 59 \\
\hline Service new starts & 36054 & 0.071 & 0.46 & 0 & 51 & 14021 & 0.072 & 0.33 & 0 & 8 \\
\hline \multicolumn{11}{|l|}{ Demographic and Business Characteristics } \\
\hline Population & 4006 & 56.83 & 137.51 & 0 & 2105.00 & 2003 & 58.96 & 158.27 & 0 & 3316.00 \\
\hline Employment density (per acre) & 4006 & 10.34 & 76.92 & 0 & 2799.91 & 2003 & 12.09 & 65.31 & 0 & 1181.86 \\
\hline Percent existing retail businesses & 4006 & $6.8 \%$ & $19.0 \%$ & $0 \%$ & $100 \%$ & 2003 & $7.4 \%$ & $18.6 \%$ & $0 \%$ & $100 \%$ \\
\hline Percent existing manufacturing businesses & 4006 & $3.3 \%$ & $13.7 \%$ & $0 \%$ & $100 \%$ & 2003 & $2.0 \%$ & $9.6 \%$ & $0 \%$ & $100 \%$ \\
\hline Percent existing information businesses & 4006 & $1.4 \%$ & $8.6 \%$ & $0 \%$ & $100 \%$ & 2003 & $1.8 \%$ & $9.6 \%$ & $0 \%$ & $100 \%$ \\
\hline Black non-Hispanic population percent & 4006 & $2.6 \%$ & $8.4 \%$ & $0 \%$ & $100 \%$ & 2003 & $3.6 \%$ & $8.3 \%$ & $0 \%$ & $100 \%$ \\
\hline Percent population aged 19-64 & 4006 & $36.7 \%$ & $34.8 \%$ & $0 \%$ & $100 \%$ & 2003 & $42.7 \%$ & $36.4 \%$ & $0 \%$ & $100 \%$ \\
\hline
\end{tabular}

\footnotetext{
${ }^{1}$ Values here reported for the spatial lag associated with each equation's dependent variable: first retail, then knowledge, then services.

${ }^{2}$ Defined as the central business districts of Phoenix, Tempe, Mesa, Scottsdale, and Chandler. These boundaries were obtained either from identified district boundaries - as in the case of Phoenix, which uses the "downtown core" neighborhood definition of Downtown Phoenix, Inc. (roughly a square area from Filmore Street to the Union Pacific railroad tracks on the south, and 3rd Avenue to 7th Street on the east) (2015) - or were digitized from Google Maps by drawing polygons around the major streets bounding the central commercial areas of each downtown. For Tempe, the downtown area includes all of the Tempe campus of Arizona State University, as well as downtown Mill Avenue, roughly from Rio Salado Avenue to Apache Road on the south, and Mill Avenue to Rural Road on the east. For Mesa, the area includes everything between Country Club Drive and Central Avenue and W. 1st Street and W 1st Avenue. The Scottsdale definition includes the "Entertainment District" and "Downtown Scottsdale" neighborhoods, roughly between N. Drinkwater and N. Goldwater Boulevards and Camelback Road and Osborn Road. For Chandler, the boundary runs on both sides of S. Arizona Avenue between E. Frye Road and E. Chandler Boulevard from S. Delaware Street on the east to the San Marcos Golf Course on the west. Any blocks that intersected the boundaries of these polygons were considered within a downtown business district and given a value of 1 for the variable.

${ }^{3}$ All spatial lags were computed using a first-order queen contiguity spatial weight matrix.

iv Note: The number of observations for several of these variables (e.g., EMPD, RETP, MANP, etc.) are lower, due to the fact that they are measured at only three points in time - 1990, 2000, and 2010. This ensures that the descriptive statistics shown for these variables are correctly divided only by three year-observations, rather than by twenty-five.
} 